\title{
"Being One with God Is Something That Can Be Done Without Rules": Commentary on Allan Kellehear's "Near-Death Experiences and the Pursuit of the Ideal Society"
}

\author{
Patricia S. Weibust, Ph.D. \\ University of Connecticut
}

ABSTRACT: Allan Kellehear's article is a pioneering venture exploring features of the transcendent society and comparing it with J.C. Davis's typology of ideal societies. Kellehear assumed that in the life after life there is a sociocultural ordering that can be discussed via structural functional theory and concepts; and he also assumed internal and external validity, despite evidence to the contrary in his article. I think both of these assumptions are incorrect. What we need are alternative sociocultural frameworks and alternative research strategies, possibly from the "new science."

Allan Kellehear's article, "Near-Death Experiences and the Pursuit of the Ideal Society," is a fascinating sociological adventure exploring features of the "transcendent society," the sociocultural system encountered by near-death experiencers (NDErs), and comparing it with J.C. Davis's typology of ideal societies. But I think anyone reading that text would be astounded by the paucity of data. It appeared that an 8-page article by Craig Lundahl (1981-82) on the NDEs of nine Mormons supplied the sociological description, while the material culture and values were culled from a slightly less limited literature. Nev-

Patricia S. Weibust, Ph.D., is Professor of Education at the University of Connecticut. Reprint requests should be addressed to Dr. Weibust at the Department of Educational Leadership, School of Education, U-93, University of Connecticut, 249 Glenbrook Road, Storrs, CT 06269-2093. 
ertheless, as I understand it, this truly was a pioneering venture, and in that spirit I found this paper stimulating of comments, suggestions, and questions.

The article contained a number of interrelated assumptions that in the life after life there would be a sociocultural order/ordering that could be discussed by theory and/or concepts currently in vogue in our social sciences. I would prefer to raise these as questions rather than assumptions. One NDEr, reflecting upon her experience and its relationship to organized religion, said, "From my brief encounter, I got the idea that being one with God is something that can be done without rules" (Morse and Perry, 1990, pp. 145-146).

The nine Mormons Lundahl investigated apparently were the only ones to observe social organization of the genre discussed by Kellehear. Most NDErs, many of whom have had very deep experiences, reported no sociological information. I do not believe in playing the numbers game in research, but $I$ think it is reasonable to ask if it is possible that the transcendent society was not a society, at least as we commonly know it, with no social organization, no norms, no institutions.

Accepting the assumption that there is some sort of sociocultural ordering, Kellehear used an amorphous structural-functional framework defined neither etically nor emically. He may have been reluctant to impose etic definitions, which stance I would applaud; but then he should have supplied direct quotes, "thick description," from informants so that grounded conceptualizations could have emerged. He did not do that either, and we are left in confusion: what is a society? what is meant by "transcendent"? what is the difference between society and culture, and what are values and their relationship to social action? and what is meant by social organization and process?

It might be helpful to discuss the transcendent society in terms of sociocultural theory and concepts that relate more to right-brain thinking, since it has been proposed that NDEs are located in that area of the brain and are anatomically associated with our unconscious desires and ability to dream (Morse and Perry, 1990). The work of British social anthropologist Victor W. Turner contained such theory and concepts, which enable us to focus on anti-structural and processual elements in sociocultural systems. By way of illustration, Turner described the concept of communitas:

The bonds of communitas are anti-structural in the sense that they are undifferentiated, equalitarian, direct, extant, nonrational, existential, I-thou (in Feuerbach's and Buber's sense) relationships. Com- 
munitas is spontaneous, immediate, concrete-it is not shaped by norms, it is not institutionalized, it is not abstract. (1974, p. 174).

Kellehear's study raised another intriguing question: how to best address the issue of validity in NDE research. I am involved in the current movement to redefine science, and the "new science" that is emerging will certainly contain data validation procedures far beyond those currently in fashion. Positivism, which is unable to reflect upon itself, provides us with limited tools to study limited phenomena, but such a myopic view of reality may not suffice when we explore new frontiers, as we must. I am hopeful that Kellehear will rise to this challenge and respond to standard queries about validity, which I will raise here, and/or share his thinking about alternate paths to validation.

Issues regarding internal and external validity are related. Are NDErs' accounts of the sociocultural world they encountered accurate? If accurate, did they actually approach another world, or was all or part of their experience a production staged by stimulation of a particular part of the brain, symbolic thought expressing unconscious desires (Morse and Perry, 1990)? Kellehear avoided questions of internal validity; it would have been better to have specified his position, whatever it was. One can assume such validity for purposes of this study, and/or state that at present validity is impossible to establish, or offer another way to establish it. Research that ignores these issues could appear naive.

Kellehear mentioned the question of external validity, but seemed to contradict himself and overlooked a powerful threat that also related to internal validity. He assumed that characteristics of the transcendent society were generalizable to everyone and not unique to an individual, a social group, or a culture - a markedly tenuous position. Kellehear himself described material and sociocultural differences by citing the villages and song and dance activities reported by Melanesian NDErs; but he only offered the possibilities that there were other societies or communities within the transcendent society.

Another possibility is that NDEs are somehow interconnected with experiences here on earth. It is very clear that individual, social, and cultural backgrounds of informants are directly linked to what they report from their NDEs. To cite one example, Melvin Morse and Paul Perry (1990) related the predeath visions of a 13-year-old boy, who stated: "In them, there are lots of people in the room. God is here too. He is in control, but sometimes he lets me be in control with him" (p. 
60). Incidentally, Morse's work indicated that predeath visions were the same as NDEs, which confirmed Marie-Louise von Franz's findings (1987). A second example is an account of a woman judged by Kenneth Ring (1980) to have had the deepest experience of any respondent in his study:

\begin{abstract}
"Then, suddenly, I saw my mother, who had died about nine years ago. And she was sitting-she always used to sit in her rocker, you know - she was smiling and she just sat there looking at me and she [spoke] to me in Hungarian [the language her mother had used while alive].... All I could see was marble; it was marble. It looked like marble, but it was very beautiful. And I could hear beautiful music; I can't tell you what kind, because I never heard anything like it before." (p. 63)
\end{abstract}

While the material culture and social specifics Kellehear mentioned, like moral stratification and restraint of problem groups, seemed to me no more generalizable than everyone speaking Hungarian or letting adolescents share control with God (is this Heaven???), I think he could have made a case for the "Mormon transcendent society." Another tack to take might have been to concentrate on what seemed to be universal social values in NDErs' reports, such as unconditional love, learning, and service.

Kellehear's comparison of the transcendent society with Davis's typology of ideal societies was a worthwhile exercise in that it highlighted our need to know more about social aspects of the NDE. The most glaring problem continues to be that he treated his "society" as if it were universal; he wrote that "these images do not arise from any one social group" (p. 92). Perhaps I am being overcritical, but Kellehear would have to tell readers who besides the nine Mormons saw these particular sociological phenomena.

He concluded that the transcendent society was a unique type of ideal society. I agree, but for a different reason. It was unique because there were no universal sociological features reported. This may have been because we need to expand our conceptualization of social life in the life after life. Or it may have been because these visions were only near-death, and many people experienced specific boundaries beyond which they could not or did not go; maybe what they saw was a transitional state and not the society itself.

I would conclude this commentary by expressing my appreciation for Kellehear's effort in attempting this formidable task. He has led a scouting expedition. While those of us in our armchairs can discuss it, his work more than anything was a call for many further expeditions, 
ideally provisioned with redefinitions of sociocultural phenomena and of scientific research itself.

\section{References}

Lundahl, C.R. (1981-82). The perceived other world in Mormon near-death experiences: A social and physical description. Omega, 12, 319-327.

Morse, M., and Perry, P. (1990). Closer to the light: Learning from the near-death experiences of children. New York, NY: Villard.

Ring, K. (1980). Life at death: A scientific investigation of the near-death experience. New York, NY: Coward, McCann and Geoghegan.

Turner, V.W. (1974). Dreams, fields, and metaphors. Ithaca, NY: Cornell University Press.

von Franz, M.-L. (1987). On dreams and death: A Jungian interpretation. Boston, MA: Shambhala. 